\title{
Ureteroinguinal hernia with obstructive urolithiasis
}

\author{
JuliAnne R. Rathbun ${ }^{1,2}$, Nanda Thimmappa ${ }^{3}$, Stephen H. Weinstein ${ }^{1,2}$, Katie S. Murray ${ }^{1,2}$ \\ ${ }^{1}$ Division of Urology, University of Missouri School of Medicine, Columbia, Missouri, USA; ${ }^{2}$ Department \\ of Surgery University of Missouri School of Medicine, Columbia, Missouri, USA; ${ }^{3}$ Department of \\ Radiology, University of Missouri School of Medicine, Columbia, Missouri, USA
}

\section{CASE REPORT}

A 64-year-old male was referred for elevated PSA of $13.7 \mathrm{ng} / \mathrm{mL}$. He underwent transrectal ultrasound-guided prostate biopsy and was found to have Gleason $4+4$ prostate cancer. Staging computed tomography (CT) revealed mild left renal atrophy and left hydroureteronephrosis. The dilated ureter extended down through the left inguinal canal and into the left hemiscrotum, where a $1 \mathrm{~cm}$ stone was noted within a ureteroinguinal hernia (Figure I). The right ureter was also contained within a right ureteroinguinal hernia, but was not dilated. Bone scan showed retained contrast in the left distal ureter within the hernia (Figure II). The patient endorsed mild back pain that he attributed to lifting and physical activity. He had a history of hypertension, and his creatinine had elevated to $1.7 \mathrm{mg} / \mathrm{dL}$ over the last two years. He was evaluated by general surgery, and his bilateral inguinal hernias were noted to be non-palpable.

Inguinal hernias can be direct or indirect and have the lifetime risk of development of 27-43\% in men and 3-6\% in women (1-3). Risk factors for inguinal hernia development include increased age, low body mass index (BMI) and genetic mutations altering connective tissue (1). Indirect hernia risk factors are patent processus vaginalis and increased cumulative occupational mechanical exposure (1). A unique subdivision of indirect inguinal hernias is ureteroinguinal. Of the two types of ureteroinguinal hernias, the most common are paraperitoneal $(80 \%)$, which are associated with a peritoneal evagination $(4,5)$. Extraperitoneal ureteroinguinal hernias involve the ureter alone or with retroperitoneal fat (4-6). In the literature, around 140 cases have been described, and very few of these with obstructive uropathy $(6,7)$. Management involves herniorrhaphy with a team-based approach between general surgery and urology (8). Risk of recurrence after standard repair increases with elevated intraabdominal pressures, which can be secondary to high BMI (1).

The patient underwent bilateral laparoscopic inguinal hernia repair with subsequent left ureteroscopy for his stone. His ureter was noted to be extremely elongated and tortuous after hernia repair. His creatinine peaked at $2.3 \mathrm{mg} / \mathrm{dL}$ at time of hernia repair, and then it improved to $1.6 \mathrm{mg} / \mathrm{dL}$ by the time of ureteroscopy. He has recovered well from both surgeries and is planning to undergo fluciclovine F-18 scan for further staging of his prostate cancer. His hydroureteronephrosis was persistent on his immediately post-operative CT scan.

\section{CONFLICT OF INTEREST}

None declared. 
Figure 1 - Coronal contrast-enhanced CT in nephrographic phase demonstrating left hydroureteronephrosis (*). Dilated left ureter noted to pass through inguinal canal (double arrows) and into the left hemiscrotum containing a stone (single arrow).

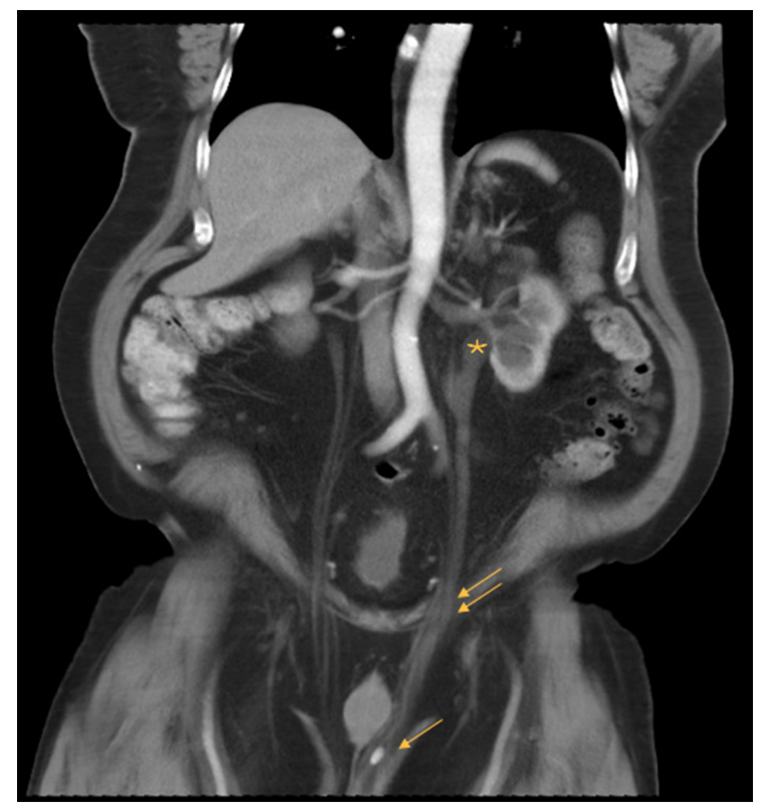

\section{REFERENCES}

1. Öberg S, Andresen K, Rosenberg J. Etiology of Inguinal Hernias: A Comprehensive Review. Front Surg. 2017:4:52.

2. Köckerling F, Simons MP. Current Concepts of Inguinal Hernia Repair. Visc Med. 2018;34:145-50.

3. HerniaSurge Group. International guidelines for groin hernia management. Hernia. 2018;22:1-165.

4. Zarraonandia Andraca A, Ríos Reboledo A, Casas Nebra J, Ponce Díaz-Reixa J, Martínez Breijo S, González Dacal J, et al. [Inguinal ureteral hernia: a clinical case]. Arch Esp Urol. 2009;62:755-7.

5. Roach SC, Moulding F, Hanbidge A. Inguinal herniation of the ureter. AJR Am J Roentgenol. 2005;185:283.

6. Yahya Z, Al-Habbal Y, Hassen S. Ureteral inguinal hernia: an uncommon trap for general surgeons. BMJ Case Rep. 2017;2017.

7. McKay JP, Organ M, Bagnell S, Gallant C, French C. Inguinoscrotal hernias involving urologic organs: A case series. Can Urol Assoc J. 2014;8:E429-32.

8. Eilber KS, Freedland SJ, Rajfer J. Obstructive uropathy secondary to ureteroinguinal herniation. Rev Urol. 2001;3:207-8.

9. $E S A, D Y J, S G G, F E J$. Inguinoscrotal herniation of the ureter: Description of five cases. Int J Surg Case Rep. 2015;14:160-3.

10. Ballard JL, Dobbs RM, Malone JM. Ureteroinguinal hernia: a rare companion of sliding inguinal hernias. Am Surg. 1991;57:720-2.
Figure 2 - Coronal bone scan showing retained contrast within left scrotal ureter (arrow) on the anterior view and slow drainage from the left kidney (double arrow) on the posterior view.

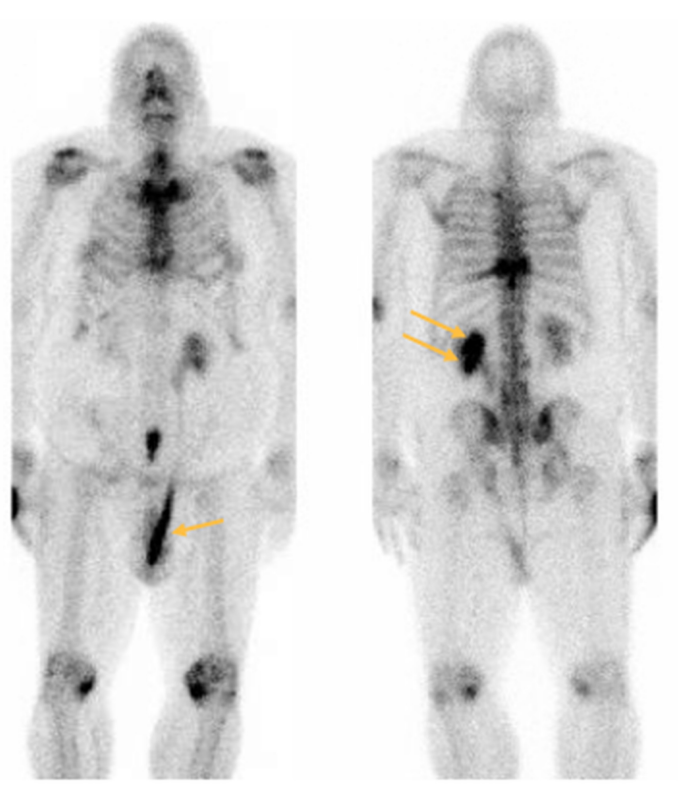

Correspondence address: JuliAnne R. Rathbun, MD Department of Surgery, Division of Urology, University of Missouri 1 Hospital Drive, Columbia, M0 65212 E-mail: rathbunj@health.missouri.edu

ARTICLE INFO

iD JuliAnne R. Rathbun http://orcid.org/0000-0002-5436-3224

Int Braz J Urol. 2020; 46: 857-8

Submitted for publication: June 24, 2019

Accepted after revision: November 06, 2019

Published as Ahead of Print: April 20, 2020 